OPEN ACCESS

Edited by:

Francois Nielsen,

University of North Carolina at Chapel Hill, USA

Reviewed by:

Sam Sloss,

Indiana University Southeast, USA

Alexandra Maryanski,

University of California

at Riverside, USA

*Correspondence:

Douglas A. Marshall

dougmarshall@southalabama.edu

Specialty section: This article was submitted to Evolutionary Sociology and Biosociology,

a section of the journal

Frontiers in Sociology

Received: 06 June 2016 Accepted: 17 August 2016 Published: 31 August 2016

Citation:

Marshall DA (2016) The Moral

Origins of God: Darwin, Durkheim, and the Homo Duplex

Theory of Theogenesis.

Front. Sociol. 1:13.

doi: 10.3389/fsoc.2016.00013

\section{The Moral Origins of God: Darwin, Durkheim, and the Homo Duplex Theory of Theogenesis}

\author{
Douglas A. Marshall* \\ Department of Sociology, Anthropology, and Social Work, University of South Alabama, Mobile, AL, USA
}

A socio-evolutionary theory of the origin of "God" is presented. Its starting point is behavioral duplexity, the fact that human beings are subject to two parallel modes of behavioral control: an older non-conscious system and a newer conscious one. The theory posits that the fabrication of, and subsequent belief in, supernatural entities ("Gods") is a predictable byproduct of the interaction of these two systems. Specifically, because human beings' profoundly social and moral faculties are primarily non-conscious, individuals experience their functioning as an external and coercive moral force. Faced with the conscious mode's need to maintain the integrity of its nomos by accounting for such experiences, individuals collectively confabulate corresponding external, coercive, and moral entities, to which they misattribute this force. In doing so, they effectively create, and re-create, their "God(s)."

\footnotetext{
Keywords: theogenesis, evolutionary sociology, sociological theory, religion, social psychology, morality, evolutionary psychology
}

Men did not begin by imagining gods ... The theory only came later, in order to explain and make intelligible to these ... minds the modes of behavior which had thus been formed.

Emile Durkheim in Giddens (1972), p. 219

Religion is a universally and uniquely human phenomenon in that all human societies possess recognizably religious beliefs and practices, but (as far as we can tell) only human societies do so. Together, these observations suggest that religion is closely related to human nature, and perhaps explicable as a function thereof. At the same time, the indubitably social enactment and implications of religion, as well as the socially determined nature of its contents, ensure that any meaningful attempt to explain religion must simultaneously be a sociological exercise. Accordingly, as the evocation of human nature to explain religion has become increasingly frequent and explicit in recent years [e.g., Boyer (2001), Atran (2002), Wilson (2002a), Bering and Johnson (2005), Dawkins (2006), Sosis (2006), Bulbulia et al. (2008), Wade (2009), Wright (2009), and Rossano (2010)], sociological concepts and mechanisms have played key roles in many such accounts.

Despite their many and diverse merits, such models invariably manifest a major sociological shortcoming, an omission which renders each's explanatory potential partial at best. This is their failure to take seriously Durkheim's seminal insights that the defining essence of religion lies in the subjectively and objectively real coercive force that it exerts on its followers, and that this force is of ultimately social origin (Durkheim, 1995[1912]).

The present paper proposes to fill this theoretical void by taking the origin of that force and its metamorphosis into "God" as its primary explanandum. By situating Durkheim's insights within a Darwinian context and fleshing them out with concepts and mechanisms borrowed from cognitive and social psychology, it aims to provide a sociological account of theogenesis that is empirically 
sound and of wide explanatory scope. Because the presentation and substantiation of this theory entails elaboration at several levels, Figure 1 provides a somewhat literal model of the theory's "structure" as an aid to its comprehension.

\section{EVOLUTIONARY GROUNDS AND BIOLOGICAL FOOTINGS}

Extant evolutionary theories of religion are too numerous and nuanced for even cursory review in the space available here, but such accounts roughly divide into two major camps. The adaptationists posit that religion confers such significant adaptive advantages that human beings have evolved a natural disposition to believe in supernatural entities and to engage in religious behavior, while the spandrelists hold that religion is too esoteric to have itself been subject to biogenetic selection pressures, explaining it instead as an unintended side effect, or "spandrel," of other traits that were selected for during evolution.

The present theory is decidedly spandrelist in positing that religion arose as a byproduct of the interaction of multiple adaptive features of human nature that originally evolved to serve other purposes. ${ }^{1}$ Specifically, it posits that "God" is a spandrel created by the interaction of three independently adaptive aspects of human nature, each of which is, in turn, a manifestation of one or the other of two core evolutionary virtues. $^{2}$

\section{Virtue 1: Responsiveness to Environmental Change}

For all of its creative potency, biogenetic evolution has at least one major shortcoming: its glacial pace. Its modus operandithe iterated differential reproduction of genotypes - operates on time scales that inevitably extend across generations.

${ }^{1}$ Which is to say neither that religions are not functional nor that they do not evolve. They clearly are [e.g., Durkheim (1995) [1912] and Wilson (2002a)] and do [e.g., Wright (2009)]. But as for all spandrels, such exaptation or evolution occurs after their emergence and thus remains irrelevant to their origins.

2"Virtue" is coined here to indicate a quality of such adaptive value that evolution consistently bends towards it. More abstract than any single trait, virtues can be achieved in multiple ways, with any trait that advances them tending to remain and proliferate within the populations that give rise to them.

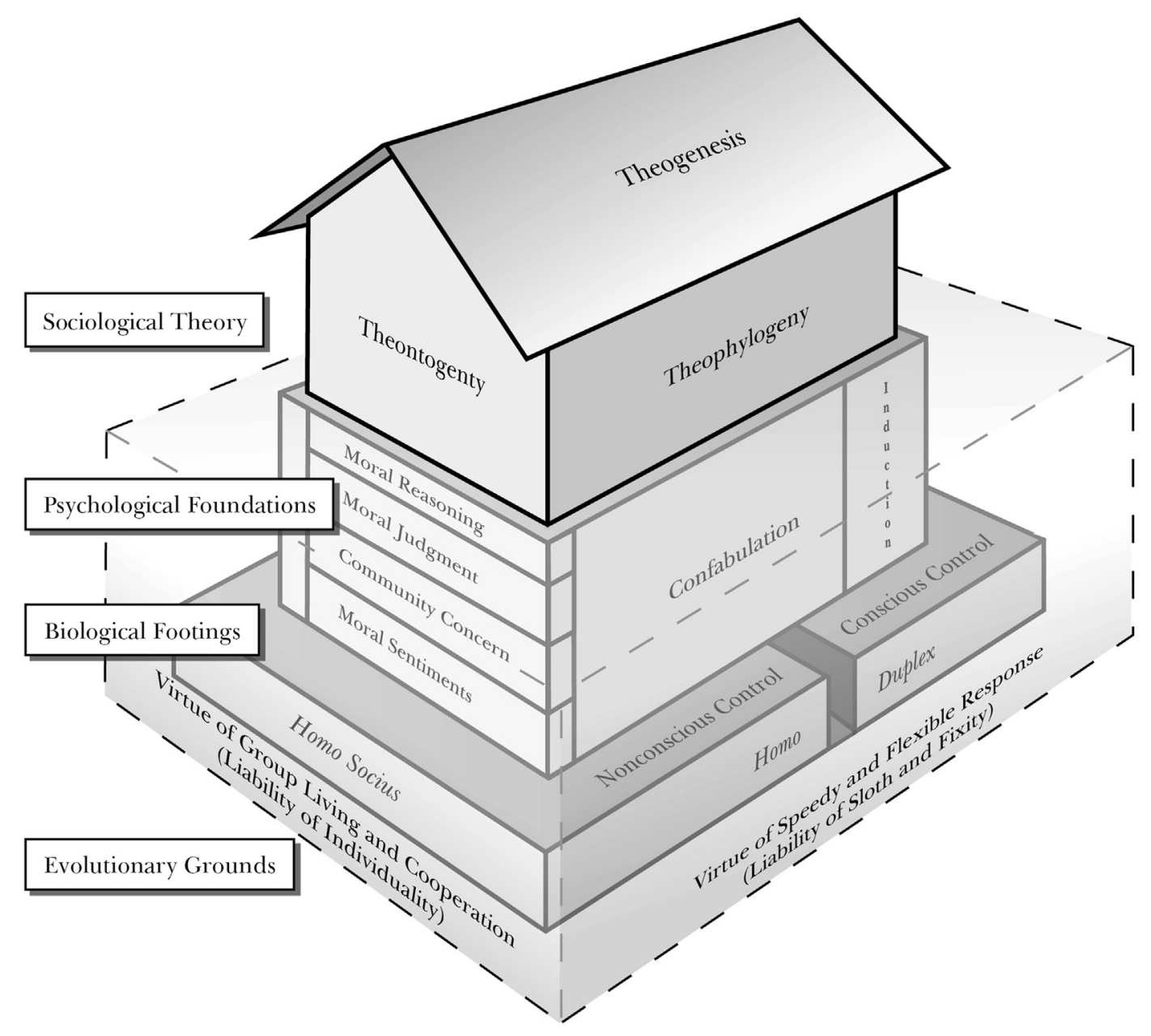

FIGURE 1 | Structure of the model. 
Accordingly, any trait that allows organisms to expedite their responsiveness to environmental events conveys a decisive advantage to any organism possessing it. ${ }^{3}$

The principal manifestation of this premium on speedy responsiveness is the ubiquity of genotypes that code for phenotypes that are themselves variable within, rather than across, individual organisms - an adaptation known, more prosaically, as "behavior" (Bonner, 1980; Wolpert, 2008). Despite the sweeping success of behavioral adaptation as a whole, continued selective pressure for fast and flexible responsiveness to the environment eventually gave rise to another, yet more rarified, innovation. Among humans (and to decreasing degrees, other primates, other mammals, and a smattering of other chordata), the sense organs that originally served to trigger behaviors in response to environmental events began also feeding information about the external environment to neural structures capable of constructing an internal model thereof.

The resulting "schema" or "nomos" (Tolman, 1948; Berger and Luckmann, 1967) constitutes a revolutionary advance in organisms' ability to respond to changes in their environment. By using the nomos to simulate their environment, organisms can anticipate changing conditions, assess competing behavioral responses, and react to novel events before they even occur. This internal mode of control - in a word, "cognition" - is the foundation of human beings' quantitatively unique capacities for reason, tool use, language, and culture. Indeed, culture itself can be fruitfully understood as a further refinement of a species' capacity for timely and flexible responsiveness - a complementary mode of adaptation that coevolves with, and as an extension of, biology (Wilson, 1998; Boyd and Richerson, 2004).

For present purposes, the crucial point is this: when the newer system of internal control arose, it did not supersede its predecessor, but was erected atop it. Possessing both the newer, nomos-driven mode of behavioral control and the older, more automatic, mode, we are Homo Duplex. ${ }^{4}$

In various forms, this dualism has long suggested itself to astute observers of human nature. As Durkheim (1964) [1914], p. 337, concludes after surveying the long history of dualistic theories of human nature: "It is not without reason that man feels himself to be double: he actually is double. There are in him two classes of states of consciousness that differ from each

${ }^{3}$ Sadly, Darwin's iconic "quote" about the virtue of responsiveness - "It is not the strongest of the species that survives, nor the most intelligent that survives. It is the one that is most adaptable to change" - turns out to be something he never actually wrote. While a compelling argument can be made that the line nevertheless accurately reflects his thoughts on the matter, the idea's provenance is less important than its empirical validity. One timely indicator thereof concerns the extent to which the current success of invasive species stems from their ability to quickly adapt to climate change. As Wolkovich et al. (2013) demonstrate, invasive species have advanced their date of first blooming to exploit ever-earlier Springtimes much more effectively than, and at the expense of, their native competitors. She notes that, "It's shocking to see how quickly the playing field is being shifted in favor of species that can be super-adaptable. The species that win are going to be those that can take advantage of new opportunities very quickly." [in Nijhuis (2013)].

${ }^{4}$ Thus, contra many critics of evolutionary sociology, human distinctiveness consists of having a conscious mode in addition to or alongside our non-conscious, not instead of it. other in origin and nature, and in the ends toward which they aim." 5 Today, such dualism stands as a foundational principle and unifying thread of the last quarter century of cognitive and social psychology. Indeed, the "dual-process models" spawned by the recognition of this duality have become the norm in the study of almost every facet of mental functioning (Wegner and Bargh, 1998; Chaiken and Trope, 1999; Uleman, 2005; Bargh and Morsella, 2008; Kahneman, 2011), even finding their way into mainstream sociological theory [e.g., Marshall $(2002,2010)$ and Vaisey (2009)].

These modes can be contrasted along multiple dimensions, but to emphasize the distinction most relevant for our purposes, I will adopt the terminology of non-conscious mode/conscious mode. Evolving long before, and in the absence of, consciousness, the non-conscious mode is invisible to consciousness, inimical to introspection, independent of conscious intention, and, due to its prelinguistic origins, effectively mute (Nisbett and Wilson, 1977; Wilson, 2002b; Bargh and Morsella, 2008). As per Vedantum (2010), it is The Hidden Brain, directing behavior via such "automatic" (Schneider and Schiffrin, 1977) means of control as reflex, affect, and intuition. Composed of multiple more-or-less autonomous modules, ${ }^{6}$ each of which evolved to surmount a particular problem, it is less a "thing" than a collection of behavioral adaptations, which are robust and strikingly effective and efficient at tasks ranging from simple homeostatic maintenance to complex feats of judgment, learning, and action of the kind usually associated with consciousness (Minsky, 1986; Reber, 1993; Wilson, 2002b; Carruthers, 2006; Vedantum, 2010; Kahneman, 2011).

By contrast, the Conscious Mode's eponymous distinction is that it operates in and through consciousness - when acting under its influence, the actor is aware of the fact that they are acting, aware of the true causes of that action, and is able to intentionally start, stop, or otherwise alter the action, hence its original "controlled" moniker (Schneider and Schiffrin, 1977). Relative to the non-conscious mode, it is a generalized processor that can simulate and operate on pretty much any domain that it can represent to itself. As such, it is highly flexible, but more effortful and slower than its non-conscious partner (Wegner and Bargh, 1998; Kahneman, 2011). Because language is itself a manifestation of its essential representationalism, the conscious mode is by far the more loquacious one.

Although these two modes of behavioral control are ideally complementary in operation, they are not necessarily so. When they do clash, the contest is decidedly one-sided, as the nonconscious system is primary to its counterpart in every sense of the term: it is evolutionarily and developmentally older. It is faster, more robust, and more closely coupled to judgment and behavior (Reber, 1993; LeDoux, 1996; Wegner and Bargh, 1998;

${ }^{5}$ Although his subsequent identification of these states as "individual" versus "social" is mistaken, his descriptions of the modes accord generally well with modern psychological accounts of them.

${ }^{6}$ While the degree of modularity in the human mind is a matter of some debate, the present model does not turn on strong modularity assumptions but only on the undisputed relative speed and competence of the non-conscious faculties to which the term "module" is typically applied. 
Bargh and Chartrand, 1999; Wilson, 2002b; Gazzanaga, 2011). Thus, though it has historically gotten top billing, the conscious mode is not only not a soloist but also the decidedly junior partner in the Homo Duplex duet.

\section{Virtue 2: Sociality}

Despite its long ascendency in Western culture, the Hobbesian view of human nature and, indeed, all of nature, as essentially individualistic and selfish has of late become empirically untenable. Its successor is a radically social view in which individualism and selfishness are evolutionary liabilities, and the capacity to live among, and cooperate with, other conspecifics is of such adaptive value that sociality arguably amounts to the "third leg" of evolution (Nowak, 2011; Wilson, 2012).

Even against this background of pervasive sociality, human beings stand out as "hypersocial" "supercooperators" (Hrdy, 2009; Bowles and Gintis, 2011; Lieberman, 2014; Warneken and Tomasello, 2006). Such rarified sociality is a cumulative achievement, an accretion of myriad social capacities and dispositions acquired throughout the evolutionary history of our species, almost all long before the advent of our conscious mode of behavioral control. Given their age and the adaptive primacy of the sociality that they make possible, it is little wonder that these continue to operate under the jurisdiction of the non-conscious mode (Turner and Maryanski, 2012; Lieberman, 2014). ${ }^{8}$ In sum, the evolutionary story of human sociality reiterates and substantiates what Durkheim (1964 [1914], 1995 [1912]) intuited over a century ago: that social forces are simultaneously among the most profound influences on human behavior and among the most invisible to actor and observer alike.

\section{PSYCHOLOGICAL FOUNDATIONS OF THE MODEL}

Three phenomena arising directly from these evolutionary grounds and biological footings form the psychological foundations, upon which the Homo Duplex theory of theogenesis depends.

\section{Induction}

Taken together, human dualism and the dominance of the non-conscious imply that an individual can experience affective states, obtain knowledge, and enact behaviors without conscious awareness as to how or why they have done so. For instance, without invoking artificially polarized distinctions between feeling and thinking, let us simply note that emotions are among the primary means by which the non-conscious mode influences

\footnotetext{
${ }^{7}$ Obvious examples include the near-impossibility of consciously suppressing reflexive behaviors such as the startle response, the phobic individual's inability to consciously overcome their non-conscious fear response, and our faces' proclivity for betraying our true feelings to others, often despite our best conscious efforts to conceal them.

${ }^{8}$ Thus, despite his prescience on other matters, Durkheim (1964) [1914] effectively gets it backwards when he identifies the "social" almost exclusively with the conscious mode. In doing so, he rather profoundly (and ironically) underestimates the extent and primacy of human sociality.
}

action (Wegner and Bargh, 1998; Turner, 2000; Vedantum, 2010), and that these, in turn, are notorious for their subjectively opaque provenance, their defiance of conscious control, and their singular power to compel action.

"Implicit knowledge" (or more colloquially, "intuition") is the second aspect of this ancient control mechanism. It occurs when individuals act on information extracted from their environment without knowing that they possess that information. The specialization and efficiency of the non-conscious means that individuals can and do accurately intuit facts about their environment without consciously detecting, or even seeking, that information (Bechara et al., 1997).

Whether via emotion, intuition, or other means of influence, the non-conscious clearly affects experience and behavior directly and independently of its conscious partner. Indeed, the entire history of experimental social psychology can justifiably be summarized as one long demonstration of individuals' proclivity for being affected by factors beyond their conscious awareness (Wegner and Bargh, 1998). As Durkheim (1963) [1897], p. 62, rightly noted, "We are, of course, very far from always knowing the reasons that make us act ...".

\section{Confabulation}

Though it is the junior partner, the conscious mode is not insubstantial. Even from within its narrow jurisdiction [mostly novel situations in which non-conscious routines break down or are as yet non-existent (Langer, 1975; Wilson, 2002b)], consciousness has radically advanced our species' ability to adapt. But such success, and the very value of consciousness as an adaptive trait, is contingent upon the individual's possession of, and confidence in, an intact nomos (Berger and Luckmann, 1967; Heine et al., 2006). When an individual becomes aware of inconsistencies between their nomos and the world it purports to represent, the model's continued viability hangs on the individual's ability to neutralize the threat posed by such anomalies.

Berger (1969) has constructed an influential and important theory of religion that emphasizes its role as a means of preserving the nomos against such threats. However, research in the "cognitive consistency" tradition reveals that discrepancies among conflicting ideas and beliefs produce, at best, inconsistent effects on individuals' attitudes and behaviors (Cooper, 2007). The crucial exception concerns cases in which the conflict is between one's beliefs and one's own behaviors, as documented by the half-century reign of Festinger's theory of cognitive dissonance (Festinger, 1957) as likely the most enduring, important, and thoroughly substantiated theory in social psychology (Cooper, 2007). As per Festinger, the discomfort arising from an awareness that one's behavior has diverged from (and is thus unexplained by) their consciously held expectations or intentions motivates individuals to reconcile the two, usually by altering their beliefs and attitudes to better align with their actions. The radical implication here is that not only do beliefs prompt action but actions can create beliefs. As Durkheim (1995) [1912], p. 372, again anticipates, "Since action cannot do without the intellect, the intellect is eventually pulled along the same way, adopting without argument the theoretical postulates the act requires." 
In combination with humans' previously discussed proclivity for induction, this post hoc needs to explain or justify behavior creates an interesting dynamic: when, due to the operation of their non-conscious mode, individuals feel, know, or act in ignorance of the true origins of these states and behaviors, their conscious mode demands that such events be accounted for. Lacking insight into their actual causes, the individual has little choice but to confabulate the entities or forces necessary to account for their experiences and actions. They do so by drawing upon context, previous experience, and a pool of culturally provided and socially endorsed legitimations to construct a plausible account of these states and behaviors (Nisbett and Wilson, 1977; Wilson and Brekke, 1994; Hirstein, 2006). Figure 2 provides a figurative illustration of the process by which actions, feelings, and cognitions are induced by the nonconscious mode, and then perceived as anomalous by the conscious mode, which then draws on and modifies culturally available constructs to confabulate explanations and justifications so as to bridge the gap between what was expected and what was experienced and preserve the nomos.

Though it deals with a different dualism, one induced by surgical separation of the left and right brain hemispheres, Gazzanaga's work with "split brain," patients provides an instructive example of confabulation, in that after surgery, the right hemisphere of his patients' brains could react appropriately to stimuli, but when asked to explain those reactions, the left hemisphere would confabulate patently incorrect justifications for them that were, however, consistent with whatever (different) stimuli it had been presented with. In the canonical example, a patient whose right hemisphere was shown a snow scene correctly pointed to a snow shovel, but when asked to explain that choice, his left hemisphere, which had seen a chicken claw rather than the snow scene, insisted that he had chosen the shovel for its usefulness in "cleaning out"

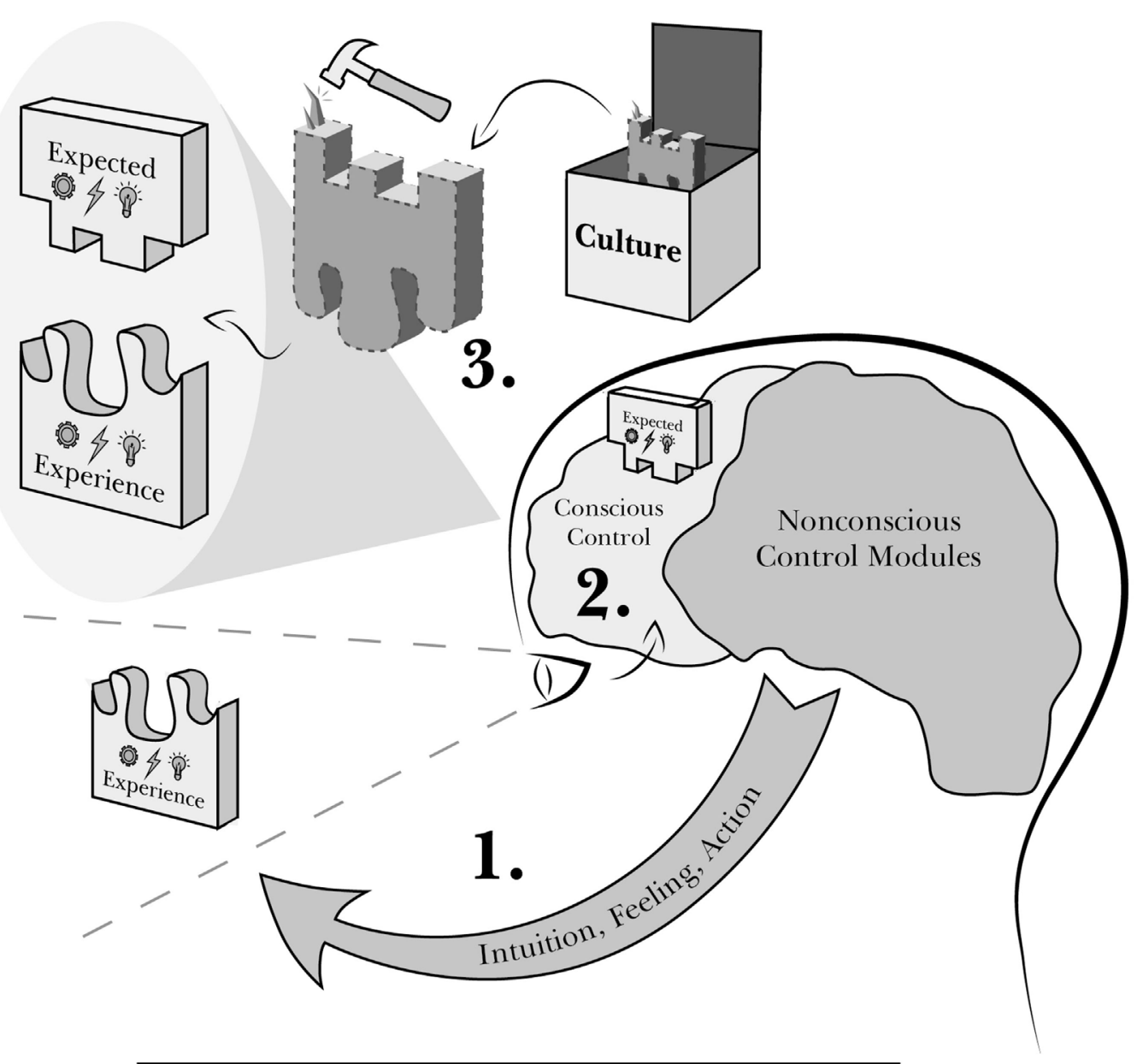

1. Induction

2. Perception of Induced Action/Feeling/Intuition

3. Confabulation 
the chicken coop. The plethora of such findings has prompted Gazzanaga (2011) to hypothesize the existence of a dedicated "interpreter module" in the brain that constantly works to string episodic experience into a coherent whole by confabulating whatever constructs are necessary to do so. To once again acknowledge the Durkheimian antecedent: "One must be on guard against literally accepting the popular explanations that men devise to account for the customs they follow, when the real causes actually escape them. It is known how these ... are constructed, it is not required that they be adequate or objective, but merely that they justify the practice" (Durkheim, 1963 [1897], p. 92).

\section{Moral Faculties}

Like the sociality of which it is a part, the idea of an innate human morality is enjoying a renaissance. Once viewed as an external and artificial restraint imposed upon an inherently immoral human nature, moral sentiments and actions are now understood to be every bit as real and natural as are the antisocial and selfish impulses that they counterbalance (Greene, 2002; DeWaal, 2006; Joyce, 2006; Lieberman, 2014; Warneken and Tomasello, 2006). As Haidt (2001), p. 826, explains, "Morality, like language, is a major evolutionary adaptation for an intensely social species, built into multiple regions of the brain and body." Also like other aspects of sociality, human morality is a primarily non-conscious faculty, with three of its four layers operating beyond the ken of consciousness (DeWaal, 2006).

The foundational layer of human morality is that of moral sentiments (DeWaal, 2006). Chief among these is empathy, our predilection for taking on the emotional states of those around us (DeWaal, 2006; Baron-Cohen, 2011; Lieberman, 2014). Empathetic mechanisms originated early in the evolution of mammals, probably as a means of inducing parents to provide the protracted and diligent care that mammalian offspring require (Haidt and Joseph, 2004). As such, they reside deep in the non-conscious (Hrdy, 2009; Turner and Maryansi, 2012). ${ }^{9}$ The other primary moral sentiment, reciprocity, insists that exchanges should be fair and that everyone should ultimately "get what they deserve." Its compulsive power among primates, and humans in particular, is a remarkably robust and widespread finding across diverse research literatures (Becker, 1986; Mauss, 1990 [1922]; DeWaal, 2006; Bowles and Gintis, 2011).

The second, and equally non-conscious, layer of human morality is what DeWaal (2006) calls "community concern." It encompasses a handful of behavioral dispositions united by their utility in helping individuals to live together in groups. They include peacemaking (DeWaal, 1990; DeWaal, 2006), anti-alpha bullying (Boehm, 2000), and the compulsion to conform to socially established rules (DeWaal, 2006; Kochanska et al., 2009).

\footnotetext{
${ }^{9}$ Empathy's non-conscious provenance is nicely illustrated by the following class demonstration: after introducing students to a plush baby seal toy named "Herbie," I produce a large pair of scissors and pretend that I am about to cut him in half. My remonstrations that Herbie is only so much velour and acrylic fiberfill do nothing to alleviate the palpable moral distress that ensues. As is typical of states originating in the non-conscious, students are acutely aware of empathy's subjective effects on their mental and emotional state, but unable to consciously override these responses, nor to explain why the fate of a patently inanimate object elicits such strong responses from them.
}

The third layer of human morality, moral judgment, also takes place almost entirely beyond the purview of consciousness (Haidt, 2001; Greene, 2002; DeWaal, 2006; Hauser, 2006; Joyce, 2006). It entails the more-or-less uniquely human capacity to perceive, pass, and be subject to, "oughts," the adaptive value of which lies in its ability to compel behavior over and against one's immediate personal preferences, in that judging an act to be "right" or "wrong" can motivate action or abstention in ways that believing it to be rational simply cannot. Like language, the inborn capacity for moral judgment is developed through an interactive social process in which native dispositions are fleshed out with a socially transmitted set of culturally specific practices and grammars. Once acquired, both language and moral judgment are thereafter deployed on an almost continuous basis with little or no conscious awareness of the underlying rules that govern it, though such rules demonstrably do exist (Haidt, 2001; Haidt and Joseph, 2004; DeWaal, 2006; Hauser, 2006).

The only clearly conscious layer of human morality - moral reasoning - is but a recent addition to a much older substrate of non-conscious moral sentiments, capacities, and predilections (Haidt, 2001; Turner and Maryanski, 2012). Although moral reasoning often plays an important role in reinforcing, calibrating, and extending the reach of moral behavior, its efforts, such as most conscious reasoning (Mercier and Sperber, 2011), focus more on legitimating non-consciously instigated actions than on actually directing action itself (Haidt, 2001; Greene, 2002; Hauser, 2006).

\section{THE HOMO DUPEX THEORY OF THEOGENESIS}

Religions are in large part recognizable as religions based on their postulation of the supernatural beings and/or forces known colloquially as "gods." Whatever the empirical status of any particular god, it can become and remain the kernel of a religion only once it attains, and for only so long as it retains, subjective reality to some discrete group of individuals. Accordingly, this paper takes theogenesis to be an essentially epistemic process by which certainty in the reality one or another "god" arises and is subsequently reproduced within the members of a group.

Though religious confidence has many buttresses, its ultimate source lies in the believer's personal experience of the entity or force in question (James, 1994 [1911], Mueller, 2010 [1873], Durkheim, 1995 [1912]). As Otto (1950) [1917] famously argues, the first-hand experience of the "numinous" precedes and precipitates all other aspects and functions of religion. It follows that if one can (1) identify the source of these experiences and (2) account for why and how they would be consistently misattributed to fabricated supernatural beings, then one might thereby explain the origin of the gods themselves.

This paper contends that the experience of the numinous and its subsequent attribution to one or more gods are both explicable as results of the interaction of the psychological foundations explicated above. In brief, it contends that the true referents of the experience of God are the states, knowledge, and behaviors induced by the moral faculties of the human non-conscious, and that the transformation of such experiences into "God" is a 
spandrel of the conscious mode's need to maintain its nomos by confabulating an entity to bridge the explanatory gap between such non-consciously mediated experiences and its extant nomos.

The attentive reader can likely anticipate the outlines of the argument to follow, but to paraphrase a commonplace, "the deity is in the details." Since this has seldom been so literally true, let us more closely consider each of the hypothesized processes in turn.

\section{The Induction of Religious Experience}

The first argument at hand is that it is the experience of states, knowledge, and behaviors originating in the non-conscious moral faculties that the construct of "God" is confabulated to explain. The context and the contents of religious experience each provide support for identifying the two.

\section{The Context of Religious Experience}

If the experience of god actually is that of the non-conscious, then its incidence should wax and wane with the non-conscious mode. An obvious example of such a pattern is the frequency with which the gods are encountered during sleep and dreams, when consciousness is quite literally dormant and the non-conscious ascendant. Beyond dreams' celebrated centrality to "primitive" religions [e.g., Tylor (1920) [1871]], their significance as a site for interacting with the gods is institutionalized by the Romans' construction of enkoimeteria - special sleeping rooms for the sick and injured where the gods were believed to visit their dreams to prescribe treatment (Henig, 1984). Among modern world religions, Judeo-Christian scripture and history is typical in the extent to which it is peppered with pivotal theophanies that take place during sleep, including Jacob's revelation at Beth-el (Genesis 28:12), Joseph's charge to take Mary as his wife (Matthew 1:20), the Magis' warning to avoid Herod (Matt. 2:12), and Constantine's dream of victory at Milvian bridge.

Religion is, in fact, the lens through which dreams are most likely to be viewed. As Bulkeley (2008), p. 3, summarizes, "The historical and cross-cultural evidence is overwhelming on this point: Religion is the primary arena in which humans have traditionally expressed their dreams." That dreams, which are of indubitably non-conscious origin, are so akin to religious experiences as to be consistently interpreted as such, which suggests that the latter might well share the former's non-conscious provenance.

It is perhaps even more telling to consider the techniques by which individuals and groups intentionally cultivate religious experiences. Religious ritual represents the most concentrated such effort, and most of its characteristic ingredients - sleep deprivation, consumption of ecstatic substances, rhythmic stimulation, spectacle, darkness, disguise, physical discomfort, co-presence, and the focusing of attention on a totemic object overlap strikingly with established means of preoccupying, distracting, or befuddling the conscious mode (Durkheim, 1995 [1912]; Marshall, 2002). Simultaneously deploying multiple such tools, religious ritual amounts to a powerful consciousnessstifling technology.

Mystical practices more generally are likewise notable for their convergence with established means of curbing consciousness.
In all of its various incarnations, meditation - the prototypical mystical exercise - is rather explicitly aimed at subjugating the conscious mind by focusing available attention on a single object, sound, or action so as to preclude conscious thought. Other common mystical practices are conspicuously effective at debilitating the conscious mode. Most dramatically, the whirling and jerking of Sufi dervishes, the mortification of Christian ascetics, and the contortions of Hindu fakirs all capitalize on the exceptional power of strong physical sensation to hijack attention and obliterate individuals' capacity for sustained conscious thought (Scarry, 1987; Baumeister, 1991). More subtly, Kaballic enumeration and the Zen Koan are among techniques that seem designed to confound consciousness by boggling the mind with illogic or competing logics so as to create what James (1994) [1911], p. 336, calls “... that vertigo of self-contradiction which is so dear to mysticism."

In sum, the contexts of religious experience suggests that, just as would be expected if the experience of God actually is that of the moral non-conscious, the gods are most likely to appear when and where the conscious mode is disadvantaged, and the non-conscious mode ascendent.

\section{The Contents of Religious Experience}

Although the specifics of the experience of god do vary across time and place, it is also true that, as Armstong (1993), p. 104, notes, “... when human beings contemplate the absolute they have very similar ideas and experiences". Of these common elements, let us consider five in particular: ineffability, otherness, superiority, coerciveness, and moral righteousness. To be sure, this is neither the only possible list of such qualities nor does it apply equally well to every known religious tradition. It is, nevertheless, defensible in that each, as elaborated in turn, is distinctive, and applicable to multiple traditions.

\section{Ineffability}

One of the most universal and salient aspects of the experience of God is its resistance to verbal description and rational understanding - in short, its ineffability (Otto, 1950 [1917]; James, 1994 [1911]; Mueller, 2010). According to the Kena Upanishad, Brahman is "... what cannot be spoken in words, but that whereby words are spoken ... what cannot be thought with the mind, but whereby the mind can think" (Mascaró, 1965, p. 51). The Buddha is equally emphatic about the inadequacy of any description of Nirvana, while the Tao Te Ching cautions that, "The reason that can be reasoned is not the eternal reason. The name that can be named is not the eternal name" (Lao-Tze, 1898, p. 97). Among Jews and early Christians such ineffability finds expression in the intentionally unpronounceable tetragrammaton, $\mathrm{YHWH}$, and, later, in the via negativa whereby God can be described only in double-negatives (e.g., "He is not non-existent") since there are no words for what God actually is. As per one of James' correspondents: "Human words cannot attain to expressing the inexpressible. Any description, however sublime it might be, could be but a profanation of the unspeakable truth" (James, 1994 [1911], p. 248).

It is not simply that words are insufficient to describe the gods, but that they, and the concepts they represent, are incompatible 
with the gods' accurate comprehension. Just as Zen Buddhism and Taoism prescribe a "first-nen" or "uncarved" experience of the world - one unmediated by conceptual thought and labels Christian mystic Gregory of Nyssa counsels that, "Every concept grasped by the mind becomes an obstacle in the quest to those who search" [in Armstrong (1993), p. 20].

Such ineffability is a predictable concomitant of nonconscious-mediated experiences as hypothesized herein. It is not only that language is but a recent imposition upon a collection of non-conscious faculties that evolved long before it did (Turner and Maryanski, 2012), but that the multiplex and parallel structure of the non-conscious renders it inimical to, and incompatible with, the unitary and serial structure that language, like conscious thought itself, requires. Accordingly, like the experience of God, the operation and contents of the non-conscious consistently defy verbal description and rational understanding (Wegner and Bargh, 1998; Bargh and Morsella, 2008; Vedantum, 2010). Thus, if as postulated here, the non-conscious is the true referent of the gods, the observed ineffability, and antipathy to rational conceptualization is exactly what one would expect of them.

This perspective sheds new light on religions' marked affinity for, and reliance upon, music and other forms of artistic expression (Armstrong, 1993). Otto (1950) [1917] holds up music as the very prototype of numinous experience, while James (1994) [1911], p. 458, contends that, “... not conceptual speech, but music, rather, is the element through which we are best spoken to by mystical truth." If, as postulated here, the experience of God arises from the non-conscious, it follows that, as non-consciously mediated experiences themselves (Haidt, 2001; Dijksterhuis and Meurs, 2006) esthetic appreciation and creation should excel as a means of conveying it, since they are akin to religious experience in ways that language and reason are not.

\section{Otherness}

The second key feature of the gods is their apparent externality to, and difference from, the believer. Though otherness may seem at first banal, it is integral both to Otto's conception of the numinous (Otto, 1950 [1917]) and to Durkheim's definition of religion (Durkheim, 1995 [1912]). Its salience to believers themselves is manifest in the Hebrew adoption of the term "Holy" (literally, "other") as their God's defining descriptor. Thus, the otherness of the gods is an apparently distinctive one.

For the present theory, which postulates an internal origin for such experiences, this otherness is distinctive precisely because it is illusory. Individuals ascribe internal versus external causation for their actions primarily on the basis of whether or not an event was present in their consciousness just before it happens (Wegner, 2002). Because non-conscious-induced actions and states are, by definition, not preceded by conscious intentions or imagery, they are easily misattributed to exogenous causes. But this creates a subjective paradox, in that even as the gods confront the believer as an external "other," they are both inescapable and intimately familiar with the individual's thoughts and actions. As David declares, "O lord, you have searched me and known me! You know when I sit down and when I rise up; You discern my thoughts from afar ... Even before a word is on my tongue, behold O Lord, you know it altogether ... Where shall I go from your Spirit? Or where shall I flee from your presence?" (Psalms 139:1-2,4,7). Otto (1950) [1917] long ago identified this paradox, the incongruous simultaneity of intimacy and externality, as one of the elements which makes the experience of God so numinously distinctive, and like ineffability, it is completely consistent with its hereinpostulated origin in the moral non-conscious: if the gods are, indeed, a manifestation of the believer's own non-conscious, then they should be intimately familiar with, and omnipresent to, the believer. From the perspective of the present theory, it is the juxtaposition of this uncanny intimacy and inescapability with the gods' (only) apparent externality that creates the highly distinctive otherness characteristic of them.

\section{Superiority}

The otherness of the Gods is of a piece with another defining characteristic - their apparent superiority to the believer. Gods are gods partly on the basis of their possession of at least some superhuman abilities and knowledge, reaching an apogee in the omniscience and omnipotence typically ascribed to the Abrahamic God. As he tells Isaiah, "Yes, the heavens are as high above the earth as my ways are above your ways, as my thoughts are above your thoughts" (Isaiah 55: 8-9). Such superiority commonly manifests itself in at least two ways, both of which are suggestive of a non-conscious origin.

First, the gods' superiority frequently comes to light via their ability to bestow previously unknown strengths and skills upon the believer, or to reveal previously unsuspected knowledge to them. Composed as it is of multiple highly specialized and wellhoned modules (Carruthers, 2006; Kahneman, 2011), the nonconscious knows things, has abilities, and possesses strengths that the conscious mode is oblivious to. When such modules manifest themselves as insights or intuitions that reflect greater knowledge than the individual consciously possesses, or as skills or stamina of which they were heretofore unaware, these foresights, insights, and abilities seem to have originated from something not only external, but superior, to the individual.

The superiority of the gods manifests itself second via the attitude of submission that they inevitably evoke in their followers. James (1994) [1911], p. 233, argues that “... self-surrender has been and always must be regarded as the vital turning point of the religious life," while Otto describes the essential emotion of religion as that of "... a creature, abased and overwhelmed by its own nothingness in contrast to that which is supreme above all creatures" (Otto, 1950 [1917], p. 10). Similarly, Berger (1969) has more recently emphasized the ubiquitous role of self-abnegation, or "masochism" in religious theodicies.

This attitude, too, is a predictable corollary of the hypothesized role of the non-conscious. Self-consciousness is, after all, a variety of consciousness. To the extent that, as predicated here, religious experience follows from the latter's eclipse by the nonconscious mode, the dissolution of self is a logical concomitant, as demonstrated by both Baumeister's work on "Escaping the Self (Baumeister, 1991) and Csikszentmihalyi's work on "Flow" (Csikszentmihalyi, 1975). In each, consciousness-disengaging activities (among which both include religious practices) deprive 
the "me" of the attentional fuel that it requires to create the sense of self. To wit, Csikszentmihalyi (1975), p. 50, 43, notes that subjects commonly report that while in flow "... you feel as though you almost don't exist...," and relates a rock-climber's testimony that while climbing, he becomes "So involved he might lose consciousness of [his] own identity and melt into the rock."

Thus, the ineffability, otherness, and superiority of the gods are each explicable via the known characteristics of nonconscious-mediated experiences. But gods are not the only supernatural construct that could be invoked to account for such qualities. For instance, the non-conscious' precociousness at detecting patterns in the environment fosters a prescience that could alternately be misattributed to ESP or alien communication (Minsky, 1986). Likewise, the ineffable, apparently external, and superior creativity that it bestows can precipitate the confabulation of, or misattribution to, such supernatural quasi-deities as the muses.

Whether or not an experience is so ascribed hinges on two further, and uniquely "godly," aspects of religious experience, both emerging from that specific subset of non-conscious elements that make up the moral faculties:

\section{Coerciveness}

As noted at the outset, the essential kernel that all religions share is their respective gods' coercive power over believers (Durkheim, 1995 [1912]). Whether that god takes the form of an embodied deity or impersonal mana, it is their ability to figuratively and literally move the individual - even over and against that person's intentions and desires - which constitutes the categorically religious aspect of religious experience. "Higher power" is the prevailing euphemism for "God" for good reason: across a spectrum extending from the fulfillment of arduous duties and loathsome commandments (e.g., Arjuna's reluctant embrace of his Dharma of war, Abraham's aborted sacrifice of Isaac), to assorted automatisms (e.g., glossolalia), to outright bodily possession (e.g., the Loa "mounting" the Voodun acolyte), the gods are most definitively recognizable as such by their apparent power to make people do things. As per the Bhagavad Gita, "the lord of all creatures stands in the heart of all, making them move hither and thither like cogs in a machine by means of his uncanny power" (18.59-61). The crucial element here is not followers' abstract belief that their God has such power, but rather their subjective experience of that power. As James (1994) [1911], p. 521, explains the persuasive impact of automatisms, "The subjects here actually feel themselves played upon by powers beyond their will. The evidence is dynamic, the God or Spirit moves the very organs of the body."

By the present theory, the roots of such coercive power lie in the uniquely efficacious motors of action available to the moral faculties of the non-conscious. Indeed, as we have seen, the adaptive value of these faculties lies precisely in their ability to ensure that individuals do those things that members of a socially interdependent species must do to survive and thrive over the long haul, even, or especially, when other courses of action might be more immediately prudent, pleasant, or profitable.

Consider, for example, the compulsive power of reciprocity. The "magical" power of a gift to cause its recipient to reciprocate to its giver is at the root of Mauss's fascination with the topic (Mauss, 1990). More broadly, we (along with some of our fellow primates) pay our debts, force others to pay theirs, and work hard to right perceived injustices despite the costs and dangers these actions can entail (Henrich et al., 2006). More darkly, we are driven to exact revenge on those who fail to reciprocate even when doing so is patently and dangerously irrational (Fehr and Gatcher, 2000; McCulloch, 2008).

The coercive power of the non-conscious moral faculties is hardly confined to reciprocity. Our predilection toward empathetic attachment impels us to provide for and protect dependents despite the dire sacrifices sometimes required to do so. Likewise, our pro-normative inclinations lead us to abide by rules even when there is no one present to enforce them and to experience guilt for doing things we do not consciously consider wrong. Finally, our judgment of some actions as "bad" puts them firmly out of bounds, however tempting they might otherwise be, while our judgment of other actions as "good" makes their execution, however unprofitable or unpleasant, an imperative duty.

In each case, the moral faculties evince a singular ability to bind us to a course of action. Thus, though we are certainly not always good, we sometimes surprise ourselves by doing the "right" thing despite our conscious intentions or expectations to the contrary. This moral imprimatur of the force of god points us toward one last signal characteristic of the gods.

\section{Moral Righteousness}

Inseparable from the gods' might to compel human behavior is their right to do so based on their identification with a transcendent moral order (James, 1994 [1911]). At the monotheistic extreme, God is cast as an indelibly moral being whose actions and imperatives are categorically good. Where the gods are more numerous and/or less uniformly beneficent, deities embodying the group's core moral values still retain their place in the pantheon (e.g., Fides, Pietas). Even ostensibly a-theistic traditions such as Taoism, Upanishadic Hinduism, and Confucianism retain this transcendent moral imperative in the form of Tao, Dharma, and the Mandate of Heaven, respectively.

Just as the gods do not represent merely a brute force, but one legitimated by an antecedent moral principle, the non-conscious moral faculties routinely cloak their outputs in moral vestments. Because the adaptive value of passing moral judgments lies in their ability to compel action as an external imperative, not only must the true internal provenance of these judgments be shielded from consciousness, but their verdicts must be reified as a matter of course. We are compelled to avoid $\mathrm{x}$ not because we have decided it is wrong or because someone says it is wrong but because it is wrong in some at least subjectively objective sense (Joyce, 2006). As per Berger (1969), the nomos must present itself as cosmos. The resulting tendency to "gild" empirical objects with the moral qualities that our intuitions have assigned to them was long ago noted by Hume (1978) [1740] and has more recently been confirmed as an essential feature of human moral perception (Greene, 2002; Nichols and Folds-Bennett, 2003).

The gods further evince their ontological relationship with human morality in that their concerns map closely onto particular non-conscious moral faculties, as again exemplified by the 
sentiment of reciprocity. The religious significance of reciprocity is reflected in such theological constructs as Karma, the "golden rule," and scriptural admonitions that, "... whatever one sows, that will he also reap" (Galatians 6:7). More indirectly, it also lies behind the evidently acute need to defend the ostensibly just (i.e., equitably reciprocal) nature of the gods from empirical experience to the contrary, as represented by "the problem of evil," and the myriad theodicies advanced to defuse the threat to faith that such inequity represents (Berger, 1969).

Reciprocity's imprint upon religion runs even deeper, however. Consider human beings' seemingly reflexive drive to make sacrifices to their gods: whether in hopes of creating an obligation on the part of a god (as per the Roman tradition of explicitly contractual sacrifice) or in hopes of paying off whatever outstanding obligations the individual or group feels they owe to their god, the sacrificial impulse is born from and part of the fundamental human moral sentiment of reciprocity.

Probably, the strongest statement of the primacy of reciprocity to the gods comes from Christianity, where even its putatively omniscient and omnipotent god can apparently find no less horrific means of balancing the moral books for humankind than through the torture-murder of his own, and only, son. It is even more significant that what was thereby attained was that god's ability to elide the dictates of reciprocity on his followers' behalf by "forgiving us our debts." His ability and willingness to provide such an escape valve from the psychological burdens imposed by human beings' possession of the moral sentiment of reciprocity is clearly a cornerstone of Christianity's appeal to its followers. ${ }^{10}$

Thus, these five features together both constitute the core properties of the construct called "God" and are singularly consistent with, and explicable as, manifestations of the operation of the moral non-conscious. Having thus established a degree of identity between the moral non-conscious and "God," what remains is to flesh out the process by which the one comes to be mistaken for the other.

\section{THE CONFABULATION OF GOD}

Though our non-conscious mode regularly induces anomalous and causally opaque states, knowledge, and behavior within or from us, most such instances are too trivial to attract our attention or to warrant explication. More salient and substantial instances of induction can usually still be resolved via fairly pedestrian acts of cognitive manipulation, but over the course of a lifetime, at least some few non-consciously induced events are of such conspicuous atypicality that their nihilation requires more heroic feats of confabulation. It is when such events involve the moral faculties that the potential for theogenesis arises, as accounting for such ineffable, external, superior, coercive, and immanently moral experiences logically necessitates the confabulation of a correspondingly ineffable, external, superior, coercive, and moral entity.

${ }^{10}$ The Christian god is not the only one to evince such dispositions, as Shiva is likewise celebrated for his power to absolve the sins of his devoted followers, and Allah answers as well to Al-Rahim (the compassionate one).
The present theory contends that theogenesis occurs when individuals and groups bridge the gap between such experiences and their expectations by confabulating a cognitive construct that, like the lynchpiece of a jigsaw puzzle, fits and fills the space between the two, integrating the disparate aspects of their experience and conjoining these with their extant nomos. This confabulated construct is, in effect, their "God."

"Theogenesis" actually subsumes two related, but distinguishable, processes - theophylogeny (the original fabrication and development of a particular concept of God) and theontogeny (the ongoing reproduction of an extant concept of God in the minds of new group members). Figure 3 updates Figure 2 into an illustration of the induction- perception-confabulation process in the specifically religious domain, and depicts both theophylogeny and theontogeny.

\section{Theophylogeny}

The actual inception of a god, as an historical event that takes place on a local scale and whose significance can usually be identified only in retrospect, is the more speculative of the two processes. However, an episode in the story of Islam - in fact, its foundational miracle - offers a possible illustration of the process: one day while meditating, Muhammed found himself compelled by a mysterious figure to "Recite!." Opening his mouth, he discovered, much to his surprise, that despite his illiteracy, he could extemporize beautiful poetry (Armstong, 1992). In consultation with his wife, Khadija, and a cousin passingly familiar with Judaism and Christianity, he identified the figure who so compelled him as the archangel Gabriel, thus initiating the process of weaving his own experience together with elements of Arabic, Jewish, and Christian culture to fabricate an effectively new deity of Al-Lah. Note the extent to which his story conforms to the model presented here - the suppression of consciousness (via meditation) is followed by a display of previously unsuspected and surprising talents, initiating a collective search for explanation in which available cultural constructs are employed to confabulate a new god.

More generally, the present theory assumes that, given their biological and cultural similarities, members of intact social groups are likely to experience similar non-consciously induced states, knowledge, and behaviors under similar circumstances. When the most saliently anomalous of these prompt members to turn to one another in search of explanation, the intersubjectivity of their experience reifies it, and thus instigates the collective project of embroidering their individual impressions of the universal moral non-conscious with the particular details and mythologies made available by their specific culture in order to confabulate their unique god.

In that such confabulation is a collective enterprise, it constitutes an - and arguably, the primordial - instance of social construction. What the present theory brings to this well-worked soil is an evolutionary and psychological base that amplifies its explanatory power. For example, by specifying the ubiquitous motivating need and instigating events that drive this particular variety of construction, as well as the uniformly human traits (dualism, propensity for induction, moral faculties, and confabulatory inclinations) that are its antecedents, the present theory can 


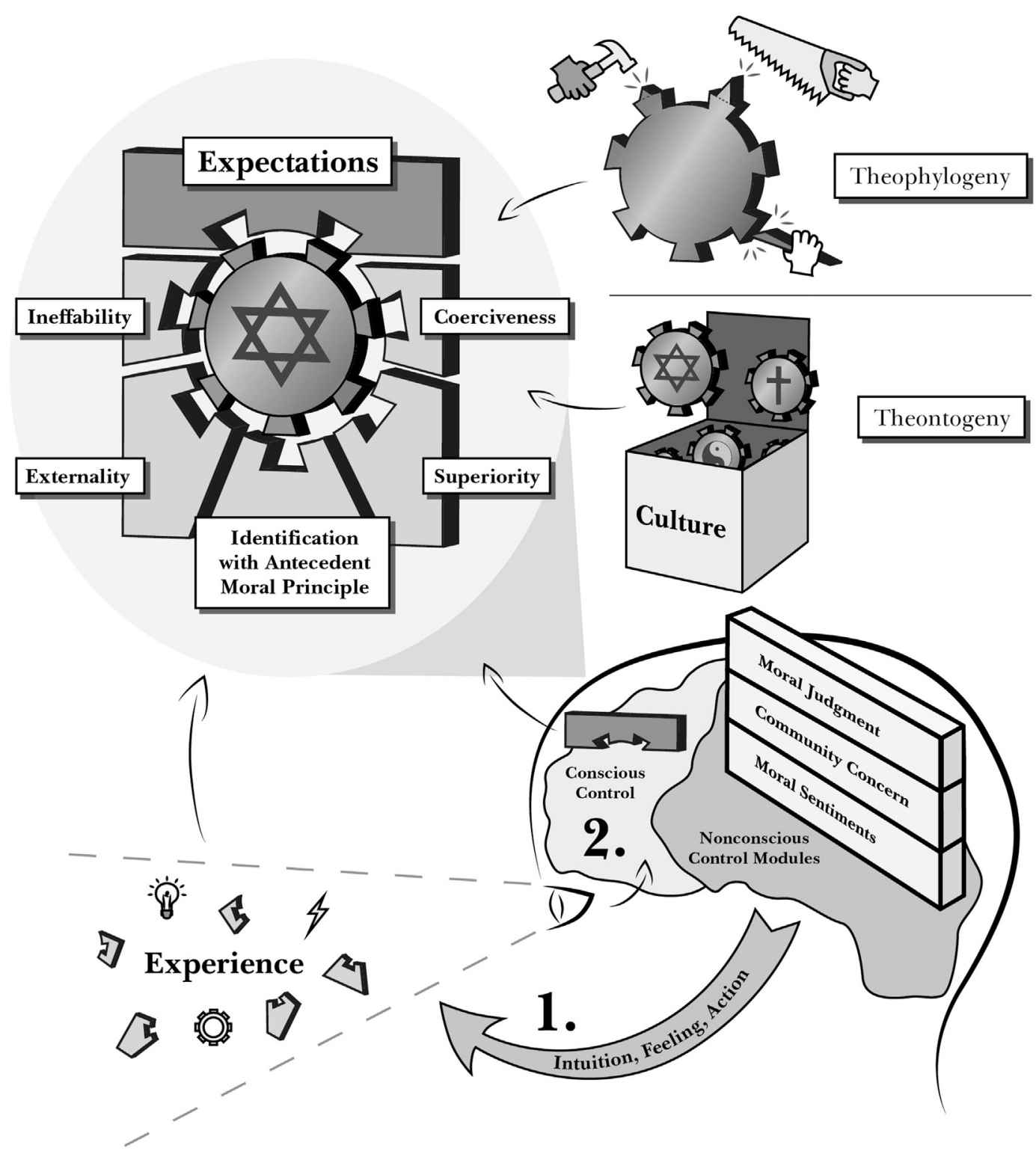

FIGURE 3 | Theogenesis.

explain why the confabulation of entities recognizable as gods is such a universal practice of human societies.

The model also helps account for some systematic variability in the nature of the entities constructed. For example, religious traditions often postulate immoral counterparts to their gods, i.e., demons (Lucifer, The Trickster in Native American lore, Shaitan in Islam, Mara in Buddhism, etc.). While the existence of such diabolical supernatural entities might seem at odds with a theory that locates the origin of the gods in the moral non-conscious, it actually underscores an important distinction between the moral non-conscious and the non-conscious as a whole. Although the non-conscious includes the moral faculties, that is not all it encompasses. Along with a host of morally neutral cognitive and social capacities (e.g., subitizing, facial recognition), it contains elements whose homeostatic and/or reproductive imperatives render them effectively "selfish" or "immoral."

Just as the non-conscious moral faculties sometimes lead us to do "right" when we do not consciously intend or expect to, these darker aspects of the non-conscious sometimes induce us to do (or feel) the "wrong" thing. No less so than moral feelings and behaviors, such non-conscious-mediated experiences incite the confabulation of an entity with which to explain them. At such times, it is useful and subjectively accurate to declare, with Flip Wilson's infamous "Geraldine" character, that “The Devil made me do it!". Like the gods, once created, such demons serve as a handy anomaly sink by 
which other surprising behaviors and abilities emerging from the non-conscious can be explained, as nearly happened in the case of Muhammed when he at first feared that his newfound affinity for impromptu poetry was the work of a Jinni, or as did happen in the case of Robert Johnson, whose newfound musical talent was ascribed to a bargain he made with the devil. The fact that immoral deities are typically perceived as diabolically seductive and deceptive rather than righteously compulsive is supportive of their here-hypothesized origins in the non-moral non-conscious, since, though partaking of the non-conscious's characteristic ineffability, externality, and superiority, they lack the coerciveness and moral imprimatur of gods emerging from the moral non-conscious and must therefore rely on other, more devious, means of influence.

\section{Theontogeny}

Though the exact dividing line is elusive, at some point, the outlines of the newly confabulated gods are well-enough established for theophylogeny to transform into theontogeny [or, as per Berger and Luckmann (1967), for objectivation to give way to internalization] as the gods are perpetually re-created in the minds of other and future group members. Theontogeny follows much the same process as theophylogeny, except that, because the need to explain anomalous states and behaviors now arises within a cultural context that provides a conceptual apparatus that is both socially pre-legitimated and closely tailored to the typical member's explanatory needs, accounting for these experiences becomes less a matter of confabulating a new entity than the simpler one of misattributing them to a pre-existing construct.

Indeed, the process of theontogeny often proceeds in reverse order from that of theophylogeny, in that, at the individual level, possession of the relevant constructs (as socialized in childhood) may precede their recruitment for nomos preservation by years or even decades. It is only once the individual experiences their own moral-non-consciously fueled anomalies and realizes the constructs' applicability to those experiences (or has it pointed out to them) that the episode is recognized as an encounter with "God." At that point, their formerly abstract religious knowledge becomes concrete religious belief. They are, in short, "born again."

Once it has thus been acquired and achieved subjective credibility, "God" readily proves its value as a tool for preserving the nomos by accounting for a spectrum of otherwise anomalous experiences emerging from the non-conscious. ${ }^{11}$ Over time, it canalizes the explanations for an ever-expanding range of phenomena back into itself to create a comprehensive and

\footnotetext{
${ }^{11}$ Though we are primarily concerned here with religious confabulation as a response to anomalies engendered by conscious/non-conscious duplexity, the efficacy of gods as a means of resolving experience/expectation discrepancies is underscored by their deployment to account for those arising from other forms of mental multiplexity. Consider, for example, the frequency with which victims of schizophrenia (literally "split mind") incorporate religious deities into their delusions, arguably as a means of accommodating their nomi to the hallucinations and compulsions characteristic of their disorder (Gearing et al., 2011).
}

self-reinforcing system. Thus, the foresights, insights, and creative syntheses produced by the non-conscious mode are interpreted as "revelations from God" or "epiphanies" (literally "encounters with God"), as when Handel exclaimed, "I think God has visited me!" upon completing his Messiah (Gangemi, 2009). Likewise, the resolve and emotional reserves that reside in the non-conscious are taken as "strength from God," as when a woman who, along with her children, recently landed a world-record alligator proclaimed: "We give all the glory to God. Ten men couldn't have done what we did ..." [in Dute (2014)]. Such utility extends as well to accounting for the behavior of others, as when John Wesley wrote abolitionist leader William Wilberforce to say that: "Unless the divine power raised you up to be as Athanasius contra mundum, I cannot see how you can go through your glorious enterprise" [in Telford (1931), p. 265].

More generally, a whole gamut of behaviors arising from the compulsive power of the moral non-conscious comes to be understood as manifestations of "God's power to move me," and the compelling beneficence that our non-conscious morality evokes in us is recast as "the love of God." Indeed, as per Feuerbach (1989) [1841], the "essence" of religion lies in its penchant for alienating natural human moral dispositions toward goodness, mercy, justice, and love from their true provenance in the individual person and misattributing them to one or another deity's power to make us behave morally, despite our putatively depraved natures.

An in vivo illustration of theontogeny comes courtesy of my local newspaper. The story concerns a woman who stopped at a convenience store while passing through a small Alabama town en route to her home in Atlanta. There, she encountered a young girl accompanied by an older man. Feeling that something about their interaction was awry, the woman contacted the local police, who, because she could not identify a concrete cause for alarm, dismissed her concerns. The woman continued home, but unable to shake her anxiety, soon returned to make further inquiries. Thus goaded into action, the police investigated and determined that the young girl was in fact a victim of severe sexual abuse by her companion, who is currently in prison for the crime (Baggett, 2007).

This woman's actions are unquestionably heroic. They are also easy to explain in terms of our model: among the non-conscious mode's most developed faculties are those for person perception and emotion detection. Thus, the pair's stilted demeanor was accurately interpreted by her non-conscious mode, but as the actual triggers were inaccessible to her conscious mode, she was unable to articulate her discomfort other than to say that something "felt wrong." Driven by her empathetic faculties to aid and protect the child, she did the right thing, but without conscious reasons to do so.

Her own account of events demonstrates the explanatory value of her culture's construct of god: "I didn't do anything really, it was God, I tried to make the feeling go away, but God said not to. It was like I could hear a voice saying 'Tracie, go back there and find that child' ... I don't deserve any credit. God had the power to save those children" (Baggett, 2007, p. A1). When, as a result of the workings of her non-conscious mode, this woman 
experienced an apparently external, ineffable, superior, coercive, and moral force, she naturally called it by the name that her culture provides for such entities: "God."

\section{CONCLUSION}

This paper has sketched a new theory of theogenesis in which "God" is a spandrel created by the interaction of humans' dual systems of behavioral control with their profoundly social and moral nature. Though it builds upon and reiterates Durkheim's seminal insights about religion, the present model is intended neither to "fulfill" or instantiate Durkheim, as it diverges from his precedent in several ways. Most obviously, its explicit evocation of evolutionary, biological, and psychological concepts and mechanisms is antithetical to the sociological "purity" that he is commonly (and mostly mistakenly) believed to have advocated. But by explicating these underpinnings, the present model significantly advances the fundamental theoretical desiderata of empirical plausibility and explanatory scope of the present theory well beyond its Durkhiemian antecedents.

As to the first, a theory can be no more credible than are its component assumptions and mechanisms. Although the present model assembles them into an original whole, all of its constituent parts are, as demonstrated herein, well-corroborated. Thus, we can be confident that Homo is indeed Duplex that human beings do possess innate moral faculties, that the non-conscious induction of states and behaviors does occur, and that human beings do confabulate in the service of nomos maintenance.

Moreover, much of the literature cited here in the service of such "modular substantiation" closely parallels these components' herein-hypothesized combinations and instantiations, such that they simultaneously constitute a kind of "analogous substantiation." For example, the cited research demonstrates not only the reality of both induction and confabulation, but also that the former often precipitates the latter as required by the model. Absent any a priori reason why the same combinations of processes should not obtain in the specifically religious domain, such evidence further vindicates the theory.

Of course, modular and analogous forms of substantiation do not obviate the need for more holistic corroboration that the postulated relationships and processes actually do obtain in the real world, and for that reason, the present paper also aggregates such evidence in the form of multiple correlations between the subjective experience of god and that of its hypothesized true referent. Though hardly definitive in and of themselves, taken together, these complementary forms of empirical substantiation lend the model an initial plausibility unusual among macro-level sociological theories.

The same attention to fundamental mechanisms that enhances empirical plausibility also expands the model's explanatory scope and power. Breaking the process of theogenesis down into its constituent mechanisms connects the present model to these mechanisms, and thereby to the extensive bodies of research and theory associated with each. Given that these literatures include such foundational and highly developed topics as cognitive dissonance, social influence, reciprocity, moral judgment, and, yes, evolution itself, the resulting network of potential applications and extensions is remarkably fertile. Some of the model's power to illuminate diverse aspects of religion has been touched on herein - e.g., the symbiosis of religion and art, the origin of demons, and the ubiquity of religious sacrifice - but these merely scratch the surface.

A genuinely fecund theory suggests new variables and mechanisms that help make sense of yet more distal phenomena, which the present model does. For instance, a logical corollary of gods that are confabulated to fill the gap between one's expected and actual behaviors is that as culturally derived assumptions of human behavior vary, so should the size of this gap, and with that, the probability and extent of theogenetic confabulation. Put simply, the less morality one expects from themselves and others, the more one needs to confabulate a moral god to resolve this discrepancy. Consider the United States: as Tocqueville observed long ago, and others have more recently confirmed, Americans are singularly likely to espouse rationalist, self-interested accounts of their own, and others, behavior (Tocqueville, 1994 [1835], Wuthnow, 1991). The present model would suggest that this cultural proclivity could contribute to the United States' relatively high degree of religiosity among developed nations (Paul, 2005), as it would require the confabulation of a larger entity to bridge the larger gap it creates between the expectation and experience of moral behavior among Americans.

Ultimately, any theory's importance is a function of its ability to change our understanding of the world by leading us to new, counterintuitive, conclusions. In the best sociological tradition, the present model inverts the conventional view of religion as a moralizing force imposed upon a fundamentally immoral (or at best amoral) human nature by arguing that it is not the gods who make humankind moral, ${ }^{12}$ but human morality that makes the gods.

Given its demonstrated empirical plausibility, wide explanatory scope, and the fact that much the same mechanisms have previously demonstrated their ability to illuminate such fundamental religious phenomena as ritual (Marshall, 2002) and the sacred (Marshall, 2010), it appears possible that the present model represents the kernel of a new and comprehensive theory of religion.

\section{AUTHOR CONTRIBUTIONS}

The author confirms being the sole contributor of this work and has approved it for publication.

\footnotetext{
${ }^{12}$ Not to say that religion does not, as per Durkheim, help people behave morally, it clearly can and does (Wilson and Musick, 1997). But like moral reasoning more generally, its effects are in addition to, rather than instead of, the moral foundations laid by the non-conscious moral faculties.
} 


\section{REFERENCES}

Armstong, K. (1992). Muhammed: A Biography of the Prophet. New York, NY: Harper Collins.

Armstrong, K. (1993). A History of God: The 4000-Year Quest of Judaism, Christianity and Islam. New York: Ballantine Books.

Atran, S. (2002). In Gods We Trust. New York: Oxford University Press.

Baggett, C. (2007). Wiley found guilty. Mobile Press-Register, 8th May: A-1,4.

Bargh, J., and Chartrand, T. (1999). The unbearable automaticity of being. Am. Psychol. 54, 462-479. doi:10.1037/0003-066X.54.7.462

Bargh, J., and Morsella, E. (2008). The unconscious mind. Perspect. Psychol. Sci. 3, 73-79. doi:10.1111/j.1745-6916.2008.00064.x

Baron-Cohen, S. (2011). The Science of Evil: On Empathy and the Origins of Cruelty. Boulder, CO: Basic Books.

Baumeister, R. (1991). Escaping the Self: Alcoholism, Spirituality, Masochism, and Other Flights from the Burden of Selfhood. New York, NY: Basic Books.

Bechara, A., Damasio, H., Tranel, D., and Damasio, A. (1997). Deciding advantageously before knowing the advantageous strategy. Science 275, 1293-1294. doi:10.1126/science.275.5304.1293

Becker, L. C. (1986). Reciprocity. Chicago: University of Chicago Press.

Berger, P. (1969). The Sacred Canopy: Elements of a Sociological Theory of Religion. Garden City, NY: Anchor Books.

Berger, P., and Luckmann, T. (1967). The Social Construction of Reality: A Treatise in the Sociology of Knowledge. Garden City, NY: Anchor Books.

Bering, J., and Johnson, D. (2005). Oh lord, you perceive my thoughts from afar: recursiveness and the evolution of supernatural agency. JCogn Culture 5, 118-142. doi:10.1163/1568537054068679

Boehm, C. (2000). "Conflict and the evolution of social control," in Evolutionary Origins of Morality: Cross-Disciplinary Perspectives, ed. L.Katz (Thorverton, UK: Imprint Academic), 79-102.

Bonner, J. (1980). The Evolution of Culture in Animals. Princeton, NJ: Princeton University Press.

Bowles, S., and Gintis, H. (2011). A Cooperative Species: Human Reciprocity and its Evolution. Princeton, NJ: Princeton University Press.

Boyd, R., and Richerson, P. J. (2004). Not by Genes Alone: How Culture Transformed Human Evolution. Chicago: University of Chicago Press.

Boyer, P. (2001). Religion Explained: The Evolutionary Origins of Religious Thought. New York: Basic Books.

Bulbulia, J., Sosis, R., Harris, E., Genet, R., Genet, C., and Wyman, K. (eds) (2008). The Evolution of Religion: Studies, Theories, and Critique. Santa Margarita, CA: Collins Foundation Press.

Bulkeley, K. (2008). Dreaming in the World's Religions: A Comparative History. New York: NYU Press.

Carruthers, P. (2006). The Architecture of the Mind. Oxford, UK: Oxford University Press.

Chaiken, S., and Trope, Y. (1999). Dual Process Theories in Social Psychology. New York, NY: Guilford Press

Cooper, J. (2007). Cognitive Dissonance: Fifty Years of a Classic Theory. Thousand Oaks, CA: SAGE.

Csikszentmihalyi, M. (1975). Beyond Boredom and Anxiety: Experiencing Flow in Work and Play. San Francisco: Jossey-Bass.

Dawkins, R. (2006). The God Delusion. Boston: Houghton Mifflin.

DeWaal, F. (1990). Peacemaking among Primates. Cambridge, MA: Harvard University Press.

DeWaal, F. (2006). Primates and Philosophers: How Morality Evolved. Princeton, NJ: Princeton University Press.

Dijksterhuis, A., and Meurs, T. (2006). Where creativity resides: the generative power of unconscious thought. Conscious. Cogn. 15, 135-146. doi:10.1016/j. concog.2005.04.007

Durkheim, E. (1963 [1897]). Incest: The Nature and Origin of the Taboo, New York: Lyle Stuart.

Durkheim, E. (1964 [1914]). "The dualism of human nature and its social conditions," in Emile Durkheim: Essays on Sociology and Philosophy, ed. K.Wolff (New York: Harper \& Row), 325-340.

Durkheim, E. (1995 [1912]). The Elementary Forms of Religious Life. New York: The Free Press.

Dute, J. (2014). Hooking a monster: Mandy Stokes and crew catch a 15-foot alligator that weighs 1011.5 lbs. Mobile Press-Register, 20th August: A04.
Fehr, E., and Gatcher, S. (2000). Fairness and retaliation: the economics of reciprocity. J. Econ. Perspect. 14, 159-181. doi:10.1257/jep.14.3.159

Festinger, L. (1957). A Theory of Cognitive Dissonance. Evanston, IL: Row, Peterson.

Feuerbach, L. (1989 [1841]). The Essence of Christianity. Amherst, NY: Prometheus Books.

Gangemi, O. (2009). Program Notes: Handel's Messiah. Oratorio Society of New York. Available at: http://www.oratoriosocietyofny.org/notesDecember.html

Gazzanaga, M. (2011). Who's in Charge?: Free Will and the Science of the Brain. New York: Harper Collins.

Gearing, R., Alonzo, D., Smolak, A., McHugh, K., Harmon, S., and Baldwin, S. (2011). Association of religion with delusions and hallucinations in the context of schizophrenia: implications for engagement and adherence. Schizophr. Res. 126, 150-163. doi:10.1016/j.schres.2010.11.005

Giddens, A. (ed.) (1972). Emile Durkheim: Selected Writings. Cambridge, UK: Cambridge University Press.

Greene, J. (2002). The Terrible, Horrible, No Good, Very Bad Truth About Morality and What To Do About It [Dissertation]. Department of Philosophy, Princeton University. Available at: http://www.wjh.harvard.edu/ jgreene/

Haidt, J. (2001). The emotional dog and it's rational tail: a social intuitionist approach to moraljudgment. Psychol.Rev. 108,814-834.doi:10.1037/0033-295X.108.4.814

Haidt, J., and Joseph, C. (2004). Intuitive ethics; how innately prepared intuitions generate culturally variable virtues. Daedalus Fall 55-66. doi:10.1162/ 0011526042365555

Hauser, M. D. (2006). Moral Minds: How Nature Designed Our Universal Sense of Right and Wrong. New York: Ecco.

Heine, S., Proulx, T., and Vohs, K. (2006). The meaning maintenance model: on the coherence of social motivations. Pers. Soc. Psychol. Rev. 10, 88-110. doi:10.1207/ s15327957pspr1002_1

Henig, M. (1984). Religion in Roman Britain. New York: St. Martin's Press.

Henrich, J., McElreath, R., Barr, A., Ensminger, J., Barrett, C., Bolyanatz, A., et al. (2006). Costly punishment across human societies. Science 312, 1767-1770. doi:10.1126/science. 1127333

Hirstein, W. (2006). Brain Fiction: Self Deception and the Riddle of Confabulation. Cambridge, MA: A Bradford Book.

Hrdy, S. B. (2009). Mothers and Others: The Evolutionary Origins of Mutual Understanding. Cambridge, MA: Belknap Press.

Hume, D. (1978 [1740]). A Treatise of Human Nature. Oxford, UK: Oxford University Press.

James, W. (1994 [1911]). The Varieties of Religious Experience. New York: The Modern Library.

Joyce, R. (2006). The Evolution of Morality. Cambridge, MA: The MIT Press.

Kahneman, D. (2011). Thinking, Fast and Slow. New York: Farrar, Strauss, Giroux.

Kochanska, G., Barry, R., Jimenez, N., Hollatz, A., and Woodard, J. (2009). Guilt and effortful control: two mechanisms that prevent disruptive developmental trajectories. J. Pers. Soc. Psychol. 97, 322-333. doi:10.1037/a0015471

Langer, E. (1975). The illusion of control. J. Pers. Soc. Psychol. 32, 311-328. doi:10.1037/0022-3514.32.2.311

Lao-Tze. (1898). Lao-Tse's Tao-The-King, trans. P. Carus (Chicago: Open Court Publishing).

LeDoux, J. (1996). The Emotional Brain: The Mysterious Underpinnings of Emotional Life. New York: Touchstone.

Lieberman, M. (2014). Social: Why Our Brains Are Wired to Connect. New York: Crown Publishers.

Marshall, D. A. (2002). Behavior, belonging, and belief: a theory of ritual practice. Sociol. Theory 20, 360-380. doi:10.1111/1467-9558.00168

Marshall, D. A. (2010). Temptation, tradition and taboo: a theory of sacralization. Sociol. Theory 28, 81-107. doi:10.1111/j.1467-9558.2009.01366.x

Mascaró, J. (trans.). (1965). The Upanishads. New York: Penguin Classics.

Mauss, M. (1990 [1922]). The Gift: Forms and Functions of Exchange in Archaic Societies. London: Routledge.

McCulloch, M. (2008). Beyond Revenge: The Evolution of the Forgiveness Instinct. San Francisco, CA: Jossey-Bass.

Mercier, H., Sperber, D. (2011). Why do humans reason? Arguments for an argumentative theory. Behavioral and Brain Sciences. 34, 57-111.

Minsky, M. (1986). The Society of Mind. New York: Simon \& Schuster.

Mueller, M. (2010 [1873]). Introduction to the Science of Religion. Whitefish, MT: Kessinger. 
Nichols, S., and Folds-Bennett, T. (2003). Are children moral objectivists? Children's judgments about moral and response-dependent properties. Cognition 90, B23-B32. doi:10.1016/S0010-0277(03)00160-4

Nijhuis, M. (2013). How climate change is helping invasive species take over. Smithsonian Magazine, December.

Nisbett, R., and Wilson, T. D. (1977). Telling more than we can know: verbal reports on mental processes. Psychol. Rev. 84, 231-259. doi:10.1037/0033-295X.84.3.231

Nowak, M. A. (2011). Supercooperators: Altruism, Evolution, and Why We Need Each Other to Succeed. New York: Free Press.

Otto, R. (1950 [1917]). The Idea of the Holy: An Inquiry into the Non-Rational Factor in the Idea of the Divine and Its Relation to the Rational. New York: Oxford University Press.

Paul, G. (2005). Cross-national correlations of quantifiable societal health with popular religiosity and secularism in the prosperous democracies. Journal of Religion \& Society 7, 1-17.

Reber, A. (1993). Implicit Learning and Tacit Knowledge: An Essay on the Cognitive Unconscious. New York: Oxford University Press.

Rossano, M. (2010). Supernatural Selection: How Religion Evolved. Oxford, UK: Oxford University Press.

Scarry, E. (1987). The Body in Pain: The Making and Unmaking of the World. Oxford, UK: Oxford University Press.

Schneider, W., and Schiffrin, R. (1977). Controlled and automatic human information processing I: detection, search and attention. Psychol. Rev. 84, 1-66. doi:10.1037/0033-295X.84.1.1

Sosis, R. (2006). "Religious behavior, badges, and bans: signaling theory and the evolution of religion," in Where God and Science Meet Vol 1, ed. P. McNamara (Westport, CT: Praeger) p. 61-86.

Telford, J. (1931). in The Letters of Rev. John Wesley A. M, ed. J. Telford VIII (London: Epworth Press).

Tocqueville, A. (1994 [1835]). Democracy in America. New York: Knopf.

Tolman, E. (1948). Cognitive maps in rats and men. Psychol. Rev. 55, 189-208. doi:10.1037/h0061626

Turner, J., and Maryanski, A. (2012). “The biology and neurology of group processes," in Biosociology and Neurosociology. Advances in Group Processes, Vol. 29, eds W. Kalkoff, S. Thye, and E. Lawler (Bingley, UK: Emerald Publishing Group) p. 1-37.

Turner, J. H. (2000). On the Origin of Human Emotions: A Sociological Inquiry into the Evolution of Human Affect. Redwood City, CA: Stanford University Press.

Tylor, E. (1920 [1871]). Primitive Culture. New York: J.P. Putnam's Sons.

Uleman, J. S. (2005). "Introduction: becoming aware of the new unconscious," in The New Unconscious, eds R. R.Hassin, J. S.Uleman, and J. A.Bargh (Oxford, UK: Oxford University Press), 3-15.
Vaisey, S. (2009). Motivation and justification: a dual-process model of culture in action. Am. J. Sociol. 114, 1675-1715. doi:10.1086/597179

Vedantum, S. (2010). The Hidden Brain: How Our Unconscious Minds Elect Presidents, Control Markets, Wage Wars, and Save Our Lives. New York, NY: Spiegel \& Grau.

Wade, N. (2009). The Faith Instinct: How Religion Evolved and Why it Endures. New York, NY: Penguin.

Warneken, F., and Tomasello, M. (2006). Altruistic helping in human infants and young chimpanzees. Science 311, 1301-1303. doi:10.1126/science.1121448

Wegner, D. (2002). The Illusion of Conscious Will. Cambridge, MA: MIT Press.

Wegner, D., and Bargh, J. (1998). "Control and automaticity in social life," in The Handbook of Social Psychology, 4th Edn, eds D. Gilbert, S. T. Fiske, and L. Gardner (Boston, MA: McGraw-Hill), 446-496.

Wilson, D. S. (2002a). Darwin's Cathedral: Evolution, Religion, and the Nature of Society. Chicago: University of Chicago Press.

Wilson, T. (2002b). Strangers to Ourselves: Discovering the Adaptive Unconscious. Cambridge, MA: Belknap.

Wilson, E. O. (1998). Consiliance: The Unity of Knowledge. New York: Vintage Books.

Wilson, E. O. (2012). The Social Conquest of Earth. New York: Liveright.

Wilson, J., and Musick, M. (1997). Who cares? Toward an integrated theory of volunteer work. Am. Sociol. Rev. 62, 694-713. doi:10.2307/2657355

Wilson, T., and Brekke, N. (1994). Mental contamination and mental correction: unwanted influences on judgments and evaluations. Psychol. Bull. 116, 117-142. doi:10.1037/0033-2909.116.1.117

Wolkovich, E. M., Davies, T., Schaefer, H., Cleland, E., Cook, B., Travers, S., et al. (2013). Temperature-dependent shifts in phenology contribute to the success of exotic species with climate change. Am. J. Bot. 100, 1407-1421. doi:10.3732/ ajb. 1200478

Wolpert, L. (2008). Six Impossible Things Before Breakfast: The Evolutionary Origins of Belief. New York: WW Norton.

Wright, R. (2009). The Evolution of God. New York: Little, Brown \& Co.

Wuthnow, R. (1991). Vocabularies of Public Life: Empirical Essays in Symbolic Structure. London: Harper Collins Academic.

Conflict of Interest Statement: The author declares that the research was conducted in the absence of any commercial or financial relationships that could be construed as a potential conflict of interest.

Copyright (c) 2016 Marshall. This is an open-access article distributed under the terms of the Creative Commons Attribution License (CC BY). The use, distribution or reproduction in other forums is permitted, provided the original author(s) or licensor are credited and that the original publication in this journal is cited, in accordance with accepted academic practice. No use, distribution or reproduction is permitted which does not comply with these terms. 